AsCLePIO. Revista de Historia de la Medicina y de la Ciencia

69 (2), julio-diciembre 2017, p196

ISSN-L:0210-4466

http://dx.doi.org/10.3989/asclepio.2017.19

DOSSIER: ESCENARIOS DE LAS PRÁCTICAS PSIQUIÁTRICAS EN AMÉRICA LATINA (SIGLOS XIX Y XX)/ OVERVIEW OF PSYCHIATRIC PRACTICES IN LATIN AMERICA (19 $9^{\text {th }}$ AND $20^{\text {th }}$ CENTURIES)

\title{
"ESTOU NO HOSPÍCIO, DEUS": PROBLEMATIZAÇÕES SOBRE A LOUCURA, O HOSPÍCIO E A PSIQUIATRIA NO DIÁRIO DE MAURA LOPES CANÇADO (BRASIL, 1959-60)
}

\author{
Yonissa Wadi \\ Universidade Estadual do Oeste do Paraná \\ yonissa.wadi@unioeste.br \\ ORCID iD: http://orcid.org/0000-0002-0224-8478
}

Recibido: 07 abril 2017; Aceptado: 12 junio 2017.

Cómo citar este artículo/Citation: Wadi, Yonissa (2017), «"Estou no Hospício, deus”: problematizações sobre a loucura, o hospício e a psiquiatria no diário de Maura Lopes Cançado (Brasil, 1959-1960)", Asclepio 69 (2): p196. doi: http://dx.doi.org/10.3989/asclepio.2017.19

RESUMO: A escritora Maura Lopes Cançado circulou no mundo dos hospitais psiquiátricos entre as décadas de 1950, 1960 e 1970. Em uma de suas internações (1959-1960), a terceira no Centro Psiquiátrico Nacional, complexo hospitalar da cidade do Rio de Janeiro, escreveu um diário que foi posteriormente publicado como o livro Hospício é Deus-Diário I. A aliança entre o vivido e a ficção, na qual transitou a narradora em seu diário, criou uma obra ímpar na perspectiva dos comentadores acadêmicos e críticos literários. No campo da história da loucura e da psiquiatria, sua obra oferece possibilidades novas de compreensão da configuração da assistência psiquiátrica, das práticas científicas e terapêuticas e dos diversos sujeitos que circularam no mundo dos hospitais psiquiátricos brasileiros, na década de 1950, operando um deslocamento em relação aos lugares tradicionais de enunciação que conhecemos. Neste artigo, escolhi observar as problematizações de Maura sobre o cotidiano institucional e o próprio ato da escrita de um diário, que oscilam entre ensinar os outros e cuidar de si. Realizei portanto, uma análise enunciativa da narrativa, que valoriza as coisas ditas por ela como uma das verdades sobre o hospital psiquiátrico, a ciência médica e suas práticas, os loucos e a loucura.

PALAVRAS-CHAVE: Maura Lopes Cançado; diário; loucura; psiquiatria; hospital psiquiátrico.

\section{"I'M IN THE HOSPICE, GOD": PROBLEMATIZATIONS ABOUT THE MADNESS, THE HOSPICE AND THE PSYCHIATRY IN THE DIARY OF MAURA LOPES CANÇADO (BRAZIL, 1959-1960)}

ABSTRACT: The writer Maura Lopes Cançado circulated in the world of the psychiatric hospitals between the 1950s, 1960s and 1970s. During one of hospitalizations (1959-1960), the third time in the National Psychiatric Center, a hospital complex in Rio de Janeiro, the writer wrote a diary that was later published as the book Hospice is God-Diary I. The bond between the live lived by her and the fiction, which the narrator transited in her diary, creating a unique work from the perspective of academic commentators and literary critics. In the history field of madness and psychiatry, this work offers new possibilities for understanding the configuration of psychiatric care, scientific and therapeutic practices and the various subjects that circulated in the world of Brazilians psychiatric hospitals, in the 1950s, operating a displacement in relation to traditional places of enunciation that are known. In this article, I chose to observe the problematizations of Maura about the institutional daily life and the fact of writing a diary, which oscillate between teaching others and the care of the self. Therefore, I did an enunciative analysis of the narrative, that values the things that were said by her as one of the truths about the psychiatric hospital, medical science and its practices, the mad and the madness.

KEY WORDS: Maura Lopes Cançado; diary; madness; psychiatry; psychiatric hospital.

Copyright: @ 2017 CSIC. Este es un artículo de acceso abierto distribuido bajo los términos de la licencia Creative Commons Attribution (CC BY) España 3.0. 
Estou de novo aqui, e isto Por que não dizer? Dói. Será por isto que venho? - Estou no Hospício, deus. E hospício é este branco sem fim, onde nos arrancam o coração a cada instante, trazem-no de volta, e o recebemos: trêmulo, exangue - e sempre outro. Hospício são as flores frias que se colam em nossas cabeças perdidas em escadarias de mármore antigo, subitamente futuro como o que não se pode ainda compreender. São mãos longas levando-nos para não sei onde-paradas bruscas, corpos sacudidos se elevando incomensuráveis: Hospício é não se sabe o quê, porque Hospício é deus.

(Cançado, 1991, p.28)

\section{ESBOÇO DE UMA HISTÓRIA}

A escritora Maura Lopes Cançado, então com 29 anos, adentrou os portões do Centro Psiquiátrico Nacional (CPN) ${ }^{1}$ pela terceira vez em 1959 (Cançado, 1991, p. 27). A epígrafe poética deste artigo é o primeiro trecho da parte datada do diário que escreveu durante o período desta terceira internação (19591960). Logo abaixo dele Maura justificou porque estava de novo ali:

Acho-me na Seção Tillemont Fontes, Hospital Gustavo Riedel, Centro Psiquiátrico Nacional, Engenho de Dentro, Rio. Vim sozinha. O que me trouxe foi a necessidade de fugir para algum lugar, aparentemente fora do mundo. (...) Havia lá fora grande incompreensão. Sobretudo pareceu-me estar sozinha. Isto faria rir a muitas pessoas: eu trabalhava no Suplemento Literário do Jornal do Brasil, onde me cercavam de grande atenção e muito carinho. (Cançado, 1991, p.28)

A procura por compreensão, a fuga da solidão, apesar da atenção e carinho que recebia em seu local de trabalho, foram justificativas para a busca da internação. Argumentos como estes já haviam sido usados anteriormente por Maura, na busca voluntária por internação em instituições psiquiátricas, e seriam repetidos outras vezes depois desta terceira internação no CPN.

Maura circulou pelo mundo dos hospitais psiquiátricos entre as décadas de 1950, 1960 e início da de 1970, até que em uma destas internações, em 1972, matou uma colega de quarto. Absolvida, por ser "considerada incapaz de atender ao caráter criminoso do fato que praticou" (Scaramella, 2015, p.1081), mas destinada a cumprir medida de segurança por oito anos, Maura deixou a carreira de paciente psiquiátrica, para iniciar uma nova carreira em penitenciárias comuns - sem acompanhamento psiquiátrico algum -, em virtude da inexistência de um manicômio judiciário feminino que pudesse recebê-la. (Autran, 1991). "O juiz decreta que até 1980 eu sou louca. A partir daí cessa minha periculosidade. Por que esta onipotência, esta onisciência do Juiz? Depois o advogado grita que eu estou ilegalmente presa. Por que então eu estou presa?", disse Maura à jornalista Margarida Autran, que a entrevistou em 1977 na Penitenciária Lemos de Brito (Autran, 1991, p.189). Em 1980 Maura foi colocada sob liberdade vigiada, passando a ser sustentada por seu filho Cesarion. Com crises quase contínuas, mudando constantemente de residência e passando por novas internações, Maura planejava escrever mas não há registros de que efetivamente tenha voltado a fazê-lo. Complicações respiratórias, decorrentes de um enfisema detectado muitos anos antes, levaram a sua morte em 1993. (Meireles, 2016)

$\mathrm{Na}$ época da terceira internação de Maura o CPN, situado no bairro do Engenho de Dentro, na cidade do Rio de Janeiro, era um complexo arquitetônico com várias unidades. Principal herdeiro do Hospício Nacional de Alienados, desativado na década anterior, e de quem recebera a maioria dos internos, o CPN erigiu-se nos terrenos da antiga Colônia de Alienadas, existente desde 1911, no referido bairro. (Jorge, 1997). Foi institucionalizado em 1944, pelo Decreto-lei 7.055, como parte da estrutura do Serviço Nacional de Doenças Mentais, dentro da lógica específica para assistência psiquiátrica na então capital da república² .

Como principal porta de entrada para as pessoas que necessitavam de assistência psiquiátrica pública, no Rio de Janeiro, o atendimento no CPN estava dividido, conforme a urgência e a especificidade, entre diversos setores e hospitais. Com a responsabilidade de oferecer os "primeiros atendimentos psiquiátricos à população" (Braga, 2013, p.27), inicialmente havia uma triagem das pessoas a partir da atribuição de um diagnóstico pela equipe do Instituto de Psiquiatria, uma de suas unidades; por outro lado, quando havia necessidade de buscar pessoas que estavam em crise aguda, o Pronto Socorro Psiquiátrico enviava uma ambulância aos locais onde estas se encontravam. ${ }^{3}$ Diferentes locais eram destinados a quem entrava por uma destas opções: os casos derivados da sífilis eram encaminhados, ou ao ambulatório de Neuro-Sífilis, ou para internação no Hospital de Neuro-Sífilis; crianças eram encaminhadas ao ambulatório de Neuro-Psiquiatria Infantil ou ao Hospital de Neuro -Psiquiatria Infantil; ao Hospital Gustavo Riedel (HGR), cujo regime era de internação mista, eram enviados os casos considerados subagudos; e os casos classificados como agudos eram enviados ao Hospital Pedro II, destinado a doentes mentais de ambos os sexos. Se no decorrer da internação uma pessoa fosse conside- 
rada, pela equipe médica, como doente crônico era encaminhada à Colônia Juliano Moreira. (Braga, 2013)

Neste final da década de 1950, o CPN era então conhecido como um grande e moderno complexo hospitalar, destino da maioria das pessoas que necessitassem de tratamento psiquiátrico público e no qual eram utilizadas as mais modernas terapêuticas no tratamento das doenças mentais, na perspectiva da psiquiatria organicista, como o eletrochoque, o coma insulínico e a lobotomia ${ }^{4}$, mas também a chamada psicoterapia de viés psicanalítico. Apesar de sua modernidade vivia os clássicos problemas das instituições manicomiais que o antecederam - problemas de todo intrínsecos ao modelo de assistência adotado, baseado em internações de longo prazo em regime fechado -, como a superlotação, a falta de mão de obra (da enfermagem à segurança), as dificuldades de transportes, entre outros problemas estruturais. (Braga, 2013)

Por outro lado, um atributo que soa paradoxal identificava o grande manicômio fundado nos anos 1940 como um lugar de explosão de uma criatividade nunca vista e, por vezes, inacreditável, porque oriunda de pessoas consideradas loucas. Esta era manifesta em trabalhos feitos por internos que frequentavam alguns dos ateliês do Serviço de Terapia Ocupacional (STO). Fora justamente a crítica às modernas terapias, consideradas por ela como extremamente violentas, que levara a psiquiatra Nise da Silveira, ao assumir a direção do STO do CPN, em 1946, a transformá-lo em um local que diferia muito do que comumente caracterizava serviços como este em diferentes hospitais. ${ }^{5}$ Segundo Nise, o setor de terapêutica ocupacional sob sua coordenação "não visaria a produção de utilidades para o hospital, mas teria por meta encontrar atividades que servissem de meios individualizados de expressão" (Dias, 2003, p.55). ${ }^{6}$ Neste sentido, o STO deixou de produzir roupas de cama e roupas para os internos, confeccionadas nos serviços de costura, ou móveis, nos serviços de marcenaria, transformandose em local de desenvolvimento de atividades recreativas (como jogos, passeios, festas, teatro) e atividades de livre expressão, desde os trabalhos manuais como crochê, tricô, bordado e tapeçaria, até a pintura, a cerâmica e a escultura. (Dias, 2003; Braga, 2013). Abria-se assim, para "clientes" do CPN, "o caminho da expressão, da criatividade, da emoção de lidar com os diferentes materiais de trabalho" (Dias, 2003, p.55) ${ }^{7}$, constituindo-se como uma verdadeira terapia para estes; e, para a psiquiatria, novas possibilidades de compreender e lidar com a esquizofrenia e outros transtornos mentais.
A partir dos ateliês de pintura e modelagem do STO erigiu-se o Museu das Imagens do Inconsciente (MII), inaugurado em 1952, que passou a reunir, cuidar e tratar das obras oriundas daqueles, muitas das quais foram consideradas por críticos importantes da época, como Mário Pedrosa, de grande valor estético. Seus produtores, os "clientes" do CPN, mantinham-se frequentando os ateliês que funcionavam dentro dele, sob coordenação da psiquiatra Nise da Silveira. (Melo, 2001; Dias, 2003; Mello, 2014). Porém, segundo alguns estudiosos, apesar do valor científico das produções gerados no STO, reconhecidas inclusive por Carl Gustav Jung (psiquiatra e psicoterapeuta suíço que fundou a psicologia analítica), e do qual se tornara seguidora Nise, as inovações terapêuticas introduzidas por esta, e seus produtos artísticos, mantiveram-se, em grande parte, ignoradas pelos médicos brasileiros seus contemporâneos (Dias, 2003, p.55), como aliás ocorria no mundo inteiro, pois, segundo Nise,

...os psiquiatras em sua grande maioria recusam a aceitação do valor artístico das pinturas e desenhos dos doentes mentais. Mantém-se irredutíveis, repetindo sempre os velhos chavões 'arte psicótica', 'arte psicopatológica', arraigados a conceitos pré-formados da psiquiatria, insistentes em procurar nessas pinturas somente reflexos de sintomas e de ruína psíquica. (Silveira, 2015, p.17)

Fazendo uso de capacidades artísticas surpreendentes, de sensibilidade e criatividade imensa, apesar de longos anos de internamento, muitos esquizofrênicos frequentadores do STO produziram imagens belíssimas, algumas dramáticas, outras harmoniosas e atraentes ao olhar. (Dias, 2003, p.60) E, como acentuei antes, na perspectiva de Nise da Silveira, o mergulho nas artes significava um notável processo terapêutico. ${ }^{8}$

Teria a escrita de Maura significado semelhante? Teria ela, por meio da narrativa no diário, exercido uma terapêutica sobre si mesma? Ou seu diário teria objetivo diferente, um objetivo pedagógico de educar outrem sobre o mundo da loucura e da institucionalização?

\section{O CAMINHO ESCOLHIDO}

Nos parágrafos anteriores, considerando alguns dos recentes estudos historiográficos sobre a instituição, tentei traçar um esboço do CPN que encontrou Maura Lopes Cançado quando lá foi internada em 1959. Daqui em diante minha intenção é adentrar este espaço, pela perspectiva de Maura, densificando aquilo que o esboço propositalmente não realiza, em sua intenção provisória de apenas delinear. A seguir explico esta intenção. 
Vinda de Minas Gerais, Maura se estabeleceu no Rio de Janeiro no início dos anos 50 e trabalhou no Ministério da Educação e em jornais, como o Correio da Manhã e o Jornal do Brasil. Neste publicou vários contos em seu Suplemento Dominical, alguns dos quais posteriormente tornaram-se parte da coletânea O Sofredor do Ver, publicada em 1968, e pela qual foi considerada a melhor escritora do ano (Cançado, 1968; Musili, 2014; Scaramella, 2010). Mas este tempo de trabalho formal, parece ser apenas um interregno entre suas várias internações ${ }^{9}$, cujo cotidiano institucional com os diferentes sujeitos que o habitavam - especialmente as mulheres loucas - e seus comportamentos, práticas, desejos, animosidades, delírios, constituem-se nos temas centrais de suas duas únicas obras literárias, a coletânea de contos e o livro Hospício é Deus - Diário I, publicado pela primeira vez em 1965, mas oriundo do diário escrito por Maura no tempo desta terceira internação, como eu disse alhures. ${ }^{10}$

A parte inicial do diário, que Maura chamou de "a metade do meu álbum" e onde diz ter procurado apresentar "a moça de dezesseis anos, bonita, rica aviadora; sem futuro - mas uma grande promessa" (Cançado, 1991, p.26), foi escrita de forma contínua, como comumente se escrevem as autobiografias, sem datação alguma, ainda que haja menção ao tempo cronológico na descrição de acontecimentos relativos a sua infância e adolescência. Entre vinte e cinco de outubro de 1959 e sete de março de 1960 - diariamente ou em saltos temporais de dias ou semanas Maura escreveu o diário propriamente dito.

Sem consenso em relação à motivação inicial para a escrita deste - teria sido incentivada pelos médicos como parte de sua "psicoterapia" ou apenas fruto de sua vontade ? -, os estudiosos parecem concordar que na narrativa de Maura há a mistura de acontecimentos vivenciados - numa escrita marcada por metáforas e ironias -, com elementos ficcionais, num diálogo constante com referências literárias que cita ou comenta, como Fernando Pessoa, Clarice Linspector, Jean Paul Sartre ou Emily Bronte. Nas palavras de Telles, a narrativa de Maura

...não se limita ao documental, é ficção literária. A escritora cria a personagem Maura Lopes Cançado. Esta, nascida em Minas Gerais, numa família tradicional e de posses, foi menina mimada. Aos cinco anos aprendera a ler sozinha e também conhecera o sexo. Mocinha, resolve ser piloto. Entra para o aeroclube, acaba destruindo o avião que a mãe lhe dera e logo se casa com um aviador. Teve um filho e antes de um ano descasou. O marido tentou interná-la, dizem, mas ela conseguiu ir para o Rio de Janeiro, deixando o filho. Ali uma vida sem freios, de inicio divertida, logo tediosa. Tornou-se jornalista e escritora elogiada, trabalhava no suplemento literário do Jornal do Brasil. Sem saber o que fazer, em turbilhão psíquico, pede para ser internada em uma casa de saúde. Diz que precisava de amor e proteção e o sanatório Ihe parecia romântico. Começa assim uma peregrinação de asilo em asilo que só terminará com sua morte. (Telles, 2008, p. 5)

A aliança entre o vivido e a ficção, na qual transita a narradora, também personagem e autora, Maura Lopes Cançado (Silva, 2011), criou uma obra ímpar na perspectiva dos comentadores acadêmicos e críticos literários, como o jornalista Francisco Assis Brasil, que acompanhou seu trajeto no Jornal do Brasil:

É bastante curioso, do ponto de vista crítico, saber que um escritor do porte de Maura Lopes Cançado tem um acervo existencial raramente encontrável em escritor brasileiro, sempre apegado a draminhas domésticos ou ligeiras crises passionais. Se seus diários tivessem sido publicados num outro país, teriam elevado o nome de Maura Lopes Cançado ao plano literário internacional. (Assis Brasil, 1973, p.105)

Já se sabe atualmente que narrativas escritas, orais, pictóricas, etc., gestadas dentro de instituições manicomiais, podem ter sido mais abundantes do que acreditávamos tempos atrás, isto graças ao um conjunto sofisticado de trabalhos que vem revelando e analisando tais escritos, procedendo assim a uma renovação da produção no campo da história da loucura e da psiquiatria. Além deste tipo de produção, em geral oriunda de pessoas infames, muitas pessoas letradas e com certa notoriedade, por sua inserção no meio artístico, literário e/ou jornalístico, como Maura, foram capazes de produzir textos de grande significado e beleza sobre suas experiências com a loucura, como o romance autobiográfico Todos os Cachorros são Azuis (2010) de Rodrigo de Souza Leão, ou o famoso Diário do Hospício; Cemitério dos Vivos ([1920] 2010) de Lima Barreto, para ficar só nos exemplos relativos à produção brasileira. ${ }^{11}$

Estes são textos similares, entre outras coisas, porque oriundos de pessoas que em algum momento viveram a experiência da loucura. Porém, ao mesmo tempo, são imensamente diferentes, desde as preocupações que movem cada escrita, até as formas e conteúdos narrativos que configuram cada obra. É certo que a maioria deles, como os citados acima, tem um tom mais ou menos acentuado de denuncia das mazelas relativas à experiência da loucura e a seus tratamentos, inclusive a da internação em verdadeiros 'cemitérios dos vivos', na metáfora de Lima (Barreto, 
2010), ou numa "cidade triste", nas palavras de Maura (Cançado, 1991, p.31), onde não há liberdade, pois "liberdade só fora do hospício", como escreveu Rodrigo (Leão, 2010, p.23). Mas cada um deles revela aspectos inusitados destas experiências constituidoras de sujeitos marcados por atributos diferentes de gênero, classe, raça, etnia e geração, circulando numa mesma espacialidade - a da cidade do Rio de Janeiro -, mas em temporalidades distintas.

Neste sentido, cada um nos oferece elementos e possibilidades novas de compreensão da configuração da assistência psiquiátrica, das práticas científicas e terapêuticas e dos diversos sujeitos que circularam no mundo dos hospitais psiquiátricos. Maura, por exemplo, escreveu suas impressões sobre o espaço de internamento nos anos finais da década de 1950, com as marcas de sua posição no mundo, como uma mulher jovem, branca, de classe média alta, erudita, escritora profissional. Contraposta a outras narrativas, através de uma bibliografia de referência sobre o tema, a narrativa de Maura constitui-se como uma forma de ampliar nosso conhecimento, no espaço e tempo correspondente, sobre relações e configurações comumente descritas por discursos hegemônicos sobre a loucura, as instituições, as políticas, os sujeitos, como as dos saberes psiquiátrico e jurídico, ou dos representantes do Estado.

A narrativa que Maura construiu em seu diário torna possível aproximações diversas, discussões inúmeras, análises em perspectivas variadas, como bem o demonstram os estudos que tomam seu diário como fonte principal. ${ }^{12}$ Neste texto escolhi trilhar um caminho: o de suas problematizações (Foucault, 2006a) sobre o cotidiano de uma instituição psiquiátrica e as práticas de seus operadores, que constroem/instituem as loucuras dos sujeitos que se encontram na condição de internos. Isto significa também adentrar em sua problematização sobre o próprio ato da escrita de um diário. Minha proposição é realizar uma análise enunciativa do diário de Maura, nos termos anunciados por Foucault (1987, p. 126), ou seja, uma análise história que se mantém ao longe de qualquer interpretação, pois "às coisas ditas, não [se] pergunta o que escondem, o que nelas estava dito e o não-dito que involuntariamente recobrem (...), mas, ao contrário, de que modo existem, o que significa para elas o fato de se terem manifestado, de terem deixado rastros (...)."

Portanto, valorizo as coisas ditas por Maura em seu diário como uma das verdades sobre o hospital psiquiátrico, a ciência médica, as práticas dos operadores dos saberes, os chamados loucos e a própria lou- cura/doença mental. As verdades ditas pelos chamados loucos - mesmo que constituídas em meio a jogos entre estes e operadores de diversos outros discursos que dizem o que é a loucura ${ }^{13}$ - operam um deslocamento em relação aos lugares tradicionais de enunciação que tão bem conhecemos. Entendo que esta é mais uma verdade possível, ainda que não tenha sido escutada ou reconhecida, durante muito tempo, como legítima em sua enunciação.

\section{PROBLEMATIZAÇÕES DE MAURA (I): ENTRE DOENTES MENTAIS E LOUCAS}

Encerrando a parte inicial de sua narrativa, que parece ter sido escrita posteriormente ao diário propriamente dito, talvez para a publicação ${ }^{14}$, Maura instituiu uma importante distinção - visualizada nos comportamentos dos internos e nas práticas divisórias no interior do hospício - entre loucura e doença mental: "É a terceira vez que me encontro no hospital. O número de doentes é grande e poucos são os loucos." (Cançado, 1991, p. 27) Ao distinguir os loucos - "distantes", "divinos", "eternos", "livres" -, dos doentes mentais, Maura fez uma elegia à loucura:

O que me assombra na loucura é a distância - os loucos parecem eternos. Nem as pirâmides do Egito, as múmias milenares, o mausoléu mais gigantesco e antigo, possuem a marca de eternidade que ostenta a loucura. (...) O louco é divino na minha tentativa fraca e angustiante de compreensão. É eterno. (...). (Cançado, 1991, p. 26)

... o que me assombra na loucura é a eternidade.

Ou: a eternidade da loucura.

Ser louco para mim é chegar lá.

Onde? - pergunto vendo dona Marina. As coisas absolutas, os mundos impenetráveis. Estas mulheres, comemos juntas. Não as conheço. Acaso alguém tocou no abstrato? (Cançado, 1991, pp. 27-28)

São poucos os verdadeiros loucos no hospício, escreveu Maura, pois a maioria dos internos são doentes mentais que lutam cotidianamente com o que se convencionou em cada época chamar doença. E esta é algo que passa a defini-los tão logo são identificados por um diagnóstico, disse ela, indicando ter clareza, pela experiência de subsequentes internações, do que Goffman (1999, p.112) chamou de carreira moral, ou seja, a hospitalização gera uma sequência de mudanças que provocam efeitos "no eu da pessoa e em seu esquemas de imagens para julgar a si mesma e aos outros". Os verdadeiros loucos estariam a salvo disto, mas não os doentes mentais: 
São poucos os loucos. A maioria compõe a parte dúbia, verdadeiros doentes mentais. Lutam contra o que se chama doença, quando justamente esta luta é o que os define: sem lado, entre o muro dos chamados normais e a liberdade do outros. Não conseguem transpor o "Muro", segundo Sartre. É a resistência. (...) Então encontramos a doença, morbidez, imensa soma de deficiências que se recusa a abandonar. Transposta a barreira, completamente definidos, passam a outro estado - que prefiro chamar de Santidade. A fase digna da coisa, a conquista de se entregar. O que aparentam é a inviolabilidade do seu mundo (...) poucos alcançam a santidade da loucura (..).

O doente, ainda preso ao mundo de onde não saiu completamente, tratado com brutalidade, desrespeito, maldade mesmo, reage. Tenta agarrar-se ao mundo de onde não saiu completamente. Apega-se a seus antigos valores, dos quais não se libertou tranquilo. Principalmente teme: a característica do doente mental é o medo (não o medo dos guardas, dos médicos. O medo de se perder de todo antes de se encontrar). (Cançado, 1991, p. 27)

Este também é o grande medo de Maura! Medo que ela problematizou ao longo do diário, no diálogo e nas ações que envolviam as outras internas, as verdadeiramente loucas e as doentes como ela, que pareciam se agarrar ao mundo de outrora, quando o mundo do hospício as tragara e pouco deixara de possibilidades para algo que permitisse a fuga da carreira iniciada. Medo que Ihe fez, também, realizar um embate constante com os médicos e os outros operadores institucionais, cujos saberes e práticas questionou. As resistências diversas, entrelaçadas às acomodações táticas, marcaram sua narrativa.

\section{PROBLEMATIZAÇÕES DE MAURA (II): OS HOSPÍ- CIOS, AS PRÁTICAS, OS OPERADORES}

A elegia à loucura cessou quando Maura narrou as diferenças entre os lugares destinados aos loucos e aos doentes mentais na estrutura de assistência psiquiátrica do Rio de Janeiro. Os primeiros - que na sua acepção estavam próximos à santidade - no mundo institucional eram os chamados crônicos, os que não tinham possibilidade alguma de cura e, a estes, era destinado o pior dos lugares no imaginário de Maura, e de algumas de suas companheiras de exílio, a Colônia Juliano Moreira:

A Colônia Juliano Moreira, para onde vão os casos incuráveis, é o terror das internadas. Ficam em Jacarepaguá e contam atrocidades acontecidas lá. Algumas guardas daqui trabalharam na Colônia. Elas dizem que é preferível morrer. Cercada de matas espessas, as doentes fugitivas são comidas por animais ferozes, contam. Composta por vários hospitais - homens e mulheres - velhos, imundos, comida infame, camas sujas com percevejos e outros bichos, muitas doentes dormem no chão - sobretudo apanham muito. (...) Dona Mercedes trabalhou lá. Contou-nos coisas escabrosas. Fico gelada: dona Júlia já indicou-me como irrecuperável. Dona Dalmatie não compreende minha sorte em não ser transferida, pois dona Júlia consegue sempre o que deseja (Cançado, 1991, p.57).

Mais desejável, apesar de seus pesares, do que a Colônia para a qual era constantemente ameaçada de ser enviada, a macroestrutura do CPM, destinada a doentes em situações agudas ou subagudas - mas contando com crônicos em suas dependências por falta de vagas naquela (Braga, 2013) -, foi também descrita por Maura e alvo de suas críticas:

Há tempos escrevi um conto, no qual dizia ser aqui "uma cidade triste de uniformes azuis e jalecos brancos". Esta cidade se compõe de seis edifícios, abrigando, normalmente, creio, dois mil e quinhentos habitantes (não estou bem certa do número). Doentes mentais, ou como tais considerados. Além do hospital onde me encontro existem: IP (Instituto de Psiquiatria), onde se fazem internações (estive lá dois meses. É caótico). Bloco Médico-Cirúrgico, Isolamento (Hospital Braule Pinto - doenças contagiosas, tuberculose principalmente), Hospital Pedro II e Instituto de Neuropsiquiatria Infantil. O isolamento fica aqui perto. À noite não consigo dormir, ouço gritos dos doentes de lá. Não compreendo um hospital abrigando tuberculosos no Engenho de Dentro, onde o clima é o mais quente do Rio. Há também o Serviço de Ocupação Terapêutica do Centro. Serve, ou devia servir, a todos os hospitais. (Cançado, 1991, p.31)

Algumas vezes as descrições mais áridas cedem lugar à descrições poéticas, nas quais sua verve literária flui aos jorros:

O hospício é árido e atentamente acordado. Em cada canto, olhos cor-de-rosa e frios espiam sem piscar. Os dias neutros. As tardes opacas, vazias, quando um ruído assusta, como vida, surgida rápida, logo apagada - extinta. As mulheres presas no pátio deixam as seções quase sempre vazias; poucas permanecem, como eu, aqui dentro o dia todo. Não frequento o pátio e isto me dá, ainda aqui, e usando o uniforme do hospital, a sensação de estar à margem. Algumas mulheres sonâmbulas andam vagas pelos corredores cinzentos. Outras sentadas no cimento fresco, olham nada, perdendo-se em distancias incomensuráveis brancas. (...) Os dormitórios vazios e impessoais são cemitérios, onde se guardam passado e futuro de tantas vidas. Cemitérios sem flor e sem piedade: cada leito mudo é um túmulo, e eu existo entre o céu e esta demência calada. (Cançado, 1991, p.71). 
Em geral, o que se lê em Hospício é Deus, com ou sem poesia, é uma descrição nítida da organização interna, do funcionamento e das relações estabelecidas naquele mundo particular, que para Maura só o cinema conseguiria retratar verdadeiramente. É assim que somos transportados ao refeitório feminino do HGR na hora do almoço, quando ele "vibra frenético e nauseante", com uma multidão de mulheres que comem ávidas, de boca aberta, com a "gordura escorrendo-lhe pelo queixo"; enquanto outras dançam com o prato na cabeça, algumas "falam, cantam, brigam, riem", até que uma guarda grita devolvendoIhes para o "sono lerdo - movimentado e denso onde vozes brotam pesadas, cheias de esquecimento. [E] o refeitório sacudido sustenta-se fantástico." (Cançado, 1991, p.71-2). Ou então, sentimos a dor daquelas, como ela mesma ou a interna Durvaldina, que amargaram dias e dias dentro de um quarto-forte após cometerem algum tipo de irregularidade, mesmo que esta fosse decorrente da sua "doença":

Durvaldina tem um olho roxo. Está toda contundida. Não sei como alguém não toma providência para que as doentes não sejam de tal maneira brutalizadas. Ainda mais que Durvaldina se acha completamente inconsciente. Hoje fui ao quarto-forte vê-la. O quartoforte fica nos fundos da seção M.B., onde Isabel está. Isabel é considerada "doente de confiança", carrega as chaves da seção, faz ocorrências e tem outras regalias. Abriu-me o quarto para que eu visse Durvaldina. Durvaldina abraçou-me chorando, pediu-me que a tirasse de lá. O quarto é abafadíssimo e sujo. Fiquei mortificada, perguntei-Ihe se sabia quem Ihe batera, e ela: “- Não. Alguém me bateu"? Dona Dalmatie disse que o professor Lopes Rodrigues, diretor-geral do Serviço Nacional de Doenças Mentais, proferiu, aqui, um discurso, na porta (nas portas, porque são três) do quarto-forte, dizendo mais ou menos isto: “- Este quarto é apenas simbólico, pois na moderna psiquiatria não o usamos". - Por que então estes quartos nunca estão vagos? (Cançado, 1991, p.117).

A crítica ao uso do quarto-forte, segundo Maura, é compartilhada por alguns poucos operadores institucionais, como D. Dalmatie a enfermeira chefe da sessão Tillemont Fontes, que teria dito a ela: "Não dão ao louco nem o direito de ser louco. Por que ninguém castiga o tuberculoso, quando é vítima de uma hemoptise e vomita sangue? Por que os 'castigos' aplicados ao doente mental quando ele se mostra sem razão?" (Cançado, 1991, p.78). O questionamento do castigo, que considera "monstruoso", leva Maura a apontar a responsabilidade médica por isto, o que denotava a "incoerência escandalosa" de suas posturas. Apesar de dizerem-se contrários aos castigos, eram de fato os médicos que os aprovavam ou mesmo que mandavam aplicá-los, diz ela. Tal postura revelava-se paradoxal aos olhos de Maura, como aos de D. Dalmatie, pois eram os próprios médicos que classificavam os doentes "acusando-os (é importante) de irresponsáveis", por meio de um diagnóstico. Então como podiam a seguir cobrar-lhes "responsabilidade" sobre determinados atos. Como era possível "punir a inconsciência", perguntava-se Maura:

De que falta pode um louco ser acusado? De ser louco? É o que venho observando e sentindo na carne. Doutor A. afirma que as guardas são ignorantes, têm muitos problemas, são também neuróticas e loucas. Naturalmente os médicos também têm problemas, são neuróticos. E loucos. Mas não foram ainda isentos, de responsabilidades perante a sociedade com a alegação de insanidade. Estes homens de aventais brancos que decidem quanto à responsabilidade ou não de tantas pessoas, deviam ter o dever de se mostrar conscientes. Não poderiam jamais exigir de alguém aquilo que Ihe negam. Como seja, a responsabilidade. Mas o fazem, afirmo. (Cançado, 1991, p.78).

Neste sentido, a crítica de Maura atinge a hierarquia da assistência dentro do HGR, e do CPN como um todo, cujas lideranças - especialmente as detentoras de um saber especial, como o diretor médico e os médicos chefes de sessão - realizavam uma mise-en-scène sem intenção de efetuar mudanças efetivas em relação aos problemas que afetavam os internos, como o sistema de castigos, para o qual contavam com o trabalho de uma espécie de tropa de choque, que falava e agia em seu nome, as enfermeiras e guardas. Em cinco de dezembro de 1959 escreveu:

Naturalmente o hospital conta com um diretor, autoridade máxima de quem se ouve falar raramente. A pessoa que fala aguça o corpo e se arma de uma dignidade terrível: " $-\mathrm{O}$ diretor quer assim. Ordens do diretor". Soa cavo, ameaçador. Ameaçador, cavo e terrível vão por conta de quem fala, arauto do rei. As doentes, não o conhecendo, não chegam a temê-lo e nenhuma the quer bem. Funcionárias se referem a ele com leviandade, dando passinhos engraçados, ao som das músicas do alto-falante e gingando os corpos mal feitos dentro do avental branco. As internadas, quase todas, duvidam um pouco da sua existência: “- Diretor? Quem é ele? É doutor J.? Não? Então, é doutor A.?" Mesmo quando dona Júlia quer se mostrar muito assanhada e importante: "- $O$ diretor quer assim", as doentes se encolhem medrosas: “- Dona Júlia quer assim".

Já falei três vezes com ele. (...). Queria protestar pelos maus tratos que me faziam. (Cançado, 1991, p.84) 
"Se me tornar escritora, até mesmo jornalista, contarei honestamente o que é um hospital de alienados", escreveu Maura no dia 12/11/1959, cerca de um mês depois de iniciar a escrita de seu diário. (Cançado, 1991, p.48) Esta afirmação também está relacionada à postura dos médicos no hospital, de quem dias depois fez um "retrato de cada um em relação às doentes". Tentou manter-se "inteiramente imparcial", restringindo-se obrigatoriamente, disse ela, aos que lhe eram conhecidos, pois trabalhavam nas sessões de mulheres, que era onde "naturalmente" se encontrava. Os médicos seus conhecidos the "aborrecem demais: com suas deficiências, ambivalências, impotências, seus problemas - ou falta de problemas - que é, nos médicos, em relação ao hospital, mais grave e comum" (Cançado, 1991, p.84), pois pouco sabem do cotidiano daquelas sobre os quais exercem seus poderes. Assim, revoltava-se com a propagação do que chamou de "uma série de mentiras sobre estes hospitais: que o tratamento é bom, tudo se tem feito para minorar o sofrimento dos doentes". (Cançado, 1991, p. 48). Afirmou que tudo,

É MENTIRA. Os médicos permanecem apenas algumas horas por dia nos hospitais, e dentro dos consultórios. Jamais visitam os refeitórios. Jamais visitam os pátios. O médico aceita, por princípio, o que qualquer guarda afirma. Se é fácil desmentir um psicopata, torna-se difícil provar que ele tem razão." (Cançado, 1991, p.48).

Algumas vezes, Maura se compadecia dos limites destes homens, limites humanos que os aproximavam dos próprios doentes com os quais lidavam. Este era o caso do médico responsável por sua sessão, chamado por ela de Doutor A., que ocupava também o lugar de vice-diretor do hospital, e com quem realizava "psicoterapia". Diálogos diversos com Doutor A., de quem se considerava enamorada, aparecem ao longo do diário, bem como diferentes posicionamentos em relação a sua competência e caráter, como lemos a seguir:

Conheci o médico e hoje falei com ele pela terceira vez. O tratamento que me faz tem o nome de psicoterapia. Não sei ainda quem é este homem de boas maneiras que me analisa. Preciso ganhar sua confiança. Deve estar tentando o mesmo comigo. (Cançado, 1991, p.31).

Conheço algumas das suas deficiências, algumas qualidades (...). Em relação às outras doentes portase muito bem, até onde pode. Sinto nele grande desamparo, ainda quando quer me ajudar. É o melhor médico do hospital, afirmo sem parcialidade. Grande entusiasta da psicanálise, vê nela a solução se buscada a tempo. É muito humano. Profissionalmente não estou a altura de julgá-lo. (Cançado, 1991, p.85)
Doutor A. não é médico para mim, sou obrigada a confessar. Considero-me uma paciente de "elite", com direito a exigir a mesma condição do terapeuta (...). O pior de tudo é que doutor A. se convenceu, firmemente de estar me tratando. Não é somente em razão de sua pouca cultura geral que se torna impossível para ele ser meu médico. Falta-lhe algo como uma capacidade de percepção mais aguda (...).

(Cançado, 1991, p.134)

Já sobre outros médicos Maura não poupou opiniões desfavoráveis, censurando e condenando seus modos de agir, especialmente na aplicação de tratamentos que julgava brutais. O médico que chama de Doutor J., por exemplo, era considerado por ela "completamente arbitrário", mantendo as sessões sob sua responsabilidade totalmente isoladas do resto do hospital, de tal forma que nem mesmo o diretor se intrometia nelas. Além disso era agressivo, de uma agressividade que se "bem dirigida seria ótima para o hospital", mas que não era, pois ele "não encara o doente mental como devia fazê-lo. Dá dezenas de eletrochoques, faz insulina e outros tratamentos - e de psicologia não entende bulhufas. Ignora se o doente tem problemas em casa, se foi traumatizado." Maura achava que se Doutor J. fosse "submetido a psicanálise, talvez se torn[asse] um bom médico". (Cançado, 1991, p.85)

Em outra passagem do diário Maura narrou acontecimentos relativos a sua segunda internação no hospital, quando ficara algum tempo em uma sessão criada para abrigar "as doentes mais agitadas e agressivas, aquelas que deveriam ir para a colônia". (Cançado, 1991, p. 44) Estando lá, após entrar em choque com a enfermeira da sessão, e jogar um copo d'água no rosto de Doutor J., Maura fora levada ao quarto-forte e, segundo ela, sua rotina, desde então resumira-se ao "seguinte regime: quarto-forte. Injeção para dormir. Violência das guardas. Mais quarto-forte. Mais violência das guardas. Quarto-forte (às vezes dormindo no chão de cimento frio). Assim sucessivamente. Fuga.". (Cançado, 1991, p.46)

Na narrativa de Maura, Doutor J. - homem de "deselegância absurda", de comportamento "lastimável" é citado como sinônimo do que havia de pior no corpo médico da instituição, com quem entrou em confronto diversas vezes:

- O senhor é arbitrário e irresponsável. Deu-me um eletrochoque quando fui sua paciente, sei que há contra indicação no meu caso. Possuo dois eletroencefalogramas anormais, fui vítima de crises convulsivas até quinze anos. Um dos eletros está dentro da minha papeleta, ou ficha. Como meu médico, o se- 
nhor devia ter-se inteirado antes, e o respeitado. Fez o eletrochoque por vingança e para castigar-me. Este método é muito usado pelos psiquiatras sei. Eletrochoque devia ser tratamento, e não instrumento de vingança em mãos de irresponsáveis. Mas aqui até as guardas ameaçam doentes com eletrochoques, trazendo-as em constante estado de tensão nervosa. (Cançado, 1991, p.42).

\section{PROBLEMATIZAÇÕES DE MAURA (III): STOS, LUGARES FORA DO LUGAR}

Ao lado dos eletrochoques, das aplicações de insulina, da reclusão no quarto-forte e da lobotomia - a que fora submetida, por exemplo, Madruga, moça rica, "inteligente, expressava-se com facilidade" e que ficou "completamente imbecilizada" (Cançado, 1991, p.88) -, que horrorizavam e amedrontavam Maura, e as quais ela resistiu de diferentes maneiras, inclusive pela escrita, havia no hospício algo digno de sua admiração. Na "cidade triste", no "cemitério sem flor e sem piedade", inacreditavelmente, brotava arte, brotava solidariedade, e isto fazia Maura gostar (as vezes) do hospital. Ela se referia ao Serviço de Ocupação Terapêutica do CPN (STO) e ao pequeno serviço coordenado pela enfermeira Dalmatie no HGR.

Como lemos páginas atrás, o STO do CPN foi implementado pela psiquiatra Nise da Silveira em 1946. Em 1959, Maura o descreveu como ocupando todo um pavilhão e composto por várias salas, como as de música, tecelagem, pintura, encadernação, bordados, além do salão de beleza e do museu, onde estavam guardados os quadros pintados por alguns dos internos do CPN. Segundo ela,

...pacientes daqui que se comparam aos maiores pintores do mundo. Futuramente, Rafael, Emídio, Isaac, Adelina, Carlos e outros terão seus nomes citados com o mesmo respeito com que se citam Van Gogh e os monstros das artes plásticas. Mesmo já se fala nestes artistas e o Suplemento Literário do Jornal do Brasil tem se interessado por eles. É deveras impressionante o poder plástico de expressão no doente mental. Perdidos no seu mundo indevassável, incapazes de comunicação verbal, totalmente dissociados, alcançam, através da pintura, o que centenas de milhares de artistas do mundo todo tentam em vão. Os artistas daqui jamais falam - a não ser através de traços e de cores. Rafael foi considerado por Júlio Braga, crítico, um dos maiores desenhistas do mundo ocidental. Aragão, chegou ao concretismo sem nenhuma comunicação com o grupo de artistas concretistas. (Cançado, 1991, p. 81).
Mesmo encantada com as possibilidades do que se produzia no STO, Maura não deixou de criticar a atuação das funcionárias, responsáveis por levar os internos de todos os hospitais do complexo para o STO que, ou não faziam isto, preferindo ficar conversando "fiado"; ou, quando o faziam, tratavam "todos como se tivessem os mesmo problemas", sem indagar "o grau de instrução de nenhum", tentando obrigá-los a "fazer trabalhos chatíssimos." Acreditava que tais comportamentos colocavam em risco tudo pelo que lutava a doutora Nise, estragando o que podia ser muito eficiente como terapêutica, portanto, gostaria de alertar a psiquiatra para as falhas que reconhecia, mas tinha dúvidas se aquela lhe daria ouvidos: "Mas como fazer-me ouvir por ela? Pode julgar que ando com mania de perseguição. Não é verdade: prescindo das funcionárias, vou sozinha porque tenho ordens do médico. Preocupo-me com as outras, presas o dia todo no hospício." (Cançado, 1991, pp. 81-82).

Maura preferia, assim, ficar no "serviçozinho" criado para as internas do HGR pela enfermeira Dalmatie, uma profissional admirada por ela e retratada sempre com carinho:

Dona Dalmatie está lutando bravamente para conseguir mantê-lo, desapontando todo o pessoal do hospital, que, evidentemente, esperava vencê-la desta vez. Ela é a funcionária mais desajustada em todo o Serviço Nacional de Doenças Mentais. É a enfermeira mais criticada e combatida do Brasil. Seu crime é digno de pena máxima num tribunal de justiça: ama sua profissão, ama os doentes e luta por eles. Jamais se alia a seus colegas, (...) entrando em choque com funcionários, até médicos. Aponta o que reconhece ser injusto, arbitrário e SÁDICO. Defende o pouco que ainda resta de direitos humanos nos psicopatas (ou como tais considerados). Dona Dalmatie é adorada pelas internas. Trabalha há vários anos nesse serviço, e, se médicos, enfermeiras e guardas não a apreciam, desconheço uma doente que não the queira bem. (Cançado, 1991, p.54).

Segundo Maura, o serviço terapêutico do HGR não tinha qualquer apoio institucional, sofrendo uma campanha contrária, por exemplo, de outra enfermeira, Dona Júlia, que dissera que ele não ia "dar em nada, porque dona Dalmatie é louca". Mas mesmo assim "esta mulher extraordinária partiu da estaca zero (...) no pátio que Ihe foi dado para o serviço, numa espécie de galpão, [e] iniciou os trabalhos sob a zombaria dos colegas". A "ocupação" era mantida com materiais trazidos de casa - "sacos desfeitos, linhas, tesouras, até máquina de fazer café" -, ou comprados por Dona Dalmatie - "linha, lã, agulha, 
o essencial para qualquer trabalho manual (...) e até cigarros para as doentes [pois] quase todas as internadas fumam, sentem-se inquietas com a falta de cigarros" -, e a colaboração das "pacientes, que só fazem bordados, tricô, etc.". (Cançado, 1991, pp. 66-67) Mesmo, com todos os empecilhos, a "ocupação" persistiu, inclusive com a preparação de uma exposição de bordados das internas, que Maura não confirmou se de fato ocorreu. O que ela fez foi ressaltar os significados deste espaço para ela e as demais mulheres que o frequentavam:

Jamais percebi um pouquinho de felicidade nas doentes deste hospital. $\mathrm{O}$ que se passa agora é inédito: quando estão trabalhando, não parecem estar num hospital de doentes mentais: alegres, rindo, trabalhando. Creio ter sido a melhor coisa que já se fez aqui em matéria de Terapêutica. Gostaria de falar ao diretor, apontar-lhe os resultados, o entusiasmo das doentes. Mas como chegar a ele, se não me ouve, me encara como psicopata - e pronto? (...) É desumano perturbar o pouquinho de felicidade desfrutado pelas pacientes. Já estive internada três vezes aqui, o hospital era um túmulo. Juro não me preocupar por mim, mas pelas outras. Tenho muitas defesas - elas não. (Cançado, 1991, p. 67).

Estou gostando do hospital. Passamos parte da manhã e da tarde trabalhando entusiasmadas, em meio a montes de lãs, tapetes, coisas e coisas: Sintome útil. Depois de duas horas, quando dona Dalmatie vai para casa, continuamos trabalhando. Se me canso e ameaço subir para a seção, todas protestam: "- Se for eu vou também". É agradável para mim e fico até a hora do jantar. Gosto de todas. Gasto mais de três carteiras de cigarros com elas. Nestas horas parece mentira que estejamos em hospital de doenças mentais: conversam, fazem brincadeiras, ninguém briga. (Cançado, 1991, p. 91).

\section{CONCLUINDO A CAMINHADA: PEDAGOGIA, TERAPÊU- TICA E VERDADE NO DIÁRIO DE UMA “HOSPICIADA"}

As problematizações produzidas por Maura em seu diário e expostas até agora, que constituíram um regime de verdade próprio sobre a vida institucional, gestadas por meio de jogos entre aquele e discursos diversos (científicos especialmente), que circulavam e circunscreviam o mundo institucional, como disse anteriormente, são marcadas por outra problematização que parece constituir a base para que as demais possam ganhar forma: a relação de Maura com a escrita, com a literatura e, assim, o sentido que dá a sua narrativa. Questão esta que levantei como central no início deste texto, ou seja: seria a narrativa no diário um exercício terapêutico subjetivante, ou um teste- munho pedagógico que visava mais do que qualquer coisa ensinar sobre o mundo da loucura e da institucionalização? Dedico-me, doravante, a refletir sobre tal buscando chegar ao fim da caminhada proposta.

Em seu livro sobre Lima Barreto, Hidalgo construiu uma síntese das questões apresentadas pelo autor em seu diário:

No relato de si realizado na condição de interno, o autor conjugou elementos dispersos e fragmentados que remetiam muitas vezes a ele mesmo. Compôs descrições do hospício, com sua hierarquia, rotina, médicos, funcionários, doentes, inserindo-se no contexto. Registrou reclamações sobre a inadaptação ao cotidiano do hospício e a revolta pela internação à sua revelia. Empreendeu uma auto-análise: fracassos, problemas familiares. Formulou críticas a sociedade como sistema (...). Inscreveu autoconfissões, desabafos existenciais, teorias sobre a loucura e literatura baseadas em sua experiência. Recolheu citações de autores diletos e informações tão práticas como o número de telefone de um amigo editor. (Hidalgo, 2008, p.50)

Vimos ao longo deste texto que praticamente tudo o que foi identificado, na citação anterior, como presente na narrativa de Lima, à exceção da internação à sua revelia, pode ser visualizado na narrativa de Maura. Além disto, também Lima apresentou alguns aspectos positivos de sua estada no hospício, que faziam - assim como para Maura -, que se sentisse fora daquele lugar, como a existência de uma boa biblioteca, onde passava seus dias lendo e escrevendo. (Barreto, 2010) Outro aspecto importante problematizado em suas narrativas diz respeito à intenção de publicização de seus diários.

Alfredo Bosi (2010) citou em seu prefácio à compilação Diário do Hospício; Cemitério dos Vivos, que Lima teria revelado a um jornalista, ainda quando interno no Hospício Nacional de Alienados, seus planos de trabalho para quando estivesse "pronto para voltar ao mundo". Destes constava a publicação de Cemitério dos Vivos baseado nas notas de seus diário, onde coligira "observações interessantíssimas para escrever um livro sobre a vida interna dos hospitais de loucos". (Lima Barreto apud Bosi, 2010, p. 33)

Tudo faz crer, e nisso concordam muitos analistas da obra de Lima Barreto, que o autor ao começar a escrever seu diário, tinha já em mente o projeto do livro. Quanto a Maura esta intenção não é tão clara. Há posições contraversas em seu texto, idas e vindas em torno da qualidade ou não de sua escrita, da validade ou não de tornar pública sua narrativa. Ainda no primeiro dia datado do diário, vinte e cinco de outubro de 1959, escreveu: 
Aqui estou de novo nesta "cidade triste", é daqui que escrevo. Não sei se rasgarei estas páginas, se as darei ao médico, se as guardarei para serem lidas mais tarde. Não sei se têm algum valor. Ignoro se tenho algum valor, ainda no sofrimento. Sou uma que veio voluntariamente para esta cidade - e talvez seja a única diferença. Com o que escrevo poderia mandar aos que "não sabem" uma mensagem do nosso mundo sombrio. Dizem que escrevo bem. Não sei. (Cançado, 1991, p.31)

Maura sabia que muitas internas escreviam, porém também que "o que escrevem não chega a ninguém", pois "parecem fazê-lo para elas mesmas". (Cançado, 1991, p.31) Ela mesma não entendia as mensagens de suas companheiras de hospital e, neste sentido, podia se tornar a tradutora adequada - com o capital que detinha, o da boa escrita -, para todas as mensagens cifradas de quem vivia no anonimato da exclusão e marginalidade do hospício. Foi assim que, em trecho de dezesseis de novembro de 1959, expressou o desejo de transformar o relato diário em um livro que permitisse aos leitores conhecer em profundidade - a profundidade daqueles que vivem a experiência da loucura e da internação -, o mundo dos hospitais psiquiátricos:

Gostaria de escrever um livro sobre o hospital e como se vive aqui. Só quem passa anonimamente por este lugar pode conhecê-lo. Eu sou apenas um prefixo no peito do uniforme. Um número a mais. À noite em nossas camas, somos contadas como se deve fazer com os criminosos nos presídios. Pretendo mesmo escrever um livro. Talvez já o esteja fazendo, não queria vivê-lo. (Cançado, 1991, p.55)

O hospício como uma prisão, uma massa de seres homogeneizados pelo uniforme numerado, um mar de camas todas iguais, a violência de práticas que atingiam a todos indiscriminadamente e um universo de dramas e sofrimentos diferentes: é algo sobre este mundo que o livro poderia ensinar. Neste sentido, transpor as páginas do diário - que foi construído e assim assumido, especialmente pelas mulheres, como um lugar privativo, no qual se poderia dizer, sem pudor, tudo o que se passava em seu íntimo -, para um livro, seria fundamental. Somente quando o relato do vivido e escrito na urgência do acontecimento transforma-se em algo diferente, um livro, que extrapola os muros da instituição, é que a função pedagógica pode se cumprir.

Por outro lado, Maura algumas vezes repudia qualquer forma de publicização do seu diário. Não simplesmente desejando mantê-lo em seu lugar tradicional, o da intimidade; mas sim, porque considera seu diário o de alguém em situação extraordinária, "uma hospiciada", como afirmou em um trecho de três de janeiro de 1960:

Meu diário é o que há de mais importante para mim. Levanto-me da cama para escrever a qualquer hora, escrevo páginas e páginas - depois rasgo mais da metade, respeitando apenas, quase sempre, aquelas em que registro fatos ou minhas relações com as pessoas. Justamente nestas relações está contida toda minha pobreza e superficialidade. Não sei como alguém, como eu, pode reagir da forma com que faço. Será deveras lastimável se este diário for publicado. Não é, absolutamente, um diário íntimo, mas tão apenas o diário de uma hospiciada, sem sentir-se com direito a escrever as enormidades que pensa, suas belezas, suas verdades. Seria verdadeiramente escandaloso meu diário íntimo - até para mim mesma, porquanto sou multivalente, não me reconheço de uma página para outra. Prefiro guardar minhas verdades, não pô-las no papel. (Cançado, 1991, p. 121-2.)

Maura recusa ao seu diário, no trecho citado, o lugar do que reconhecemos hoje como uma escrita de si (Foucault, 1992), por não percebê-lo como um lugar de autoconhecimento, o que um diário íntimo propiciaria ao desvelar os recônditos de uma pessoa, com suas enormidades, belezas e verdades, mas também, demônios e culpas. Como se lê na citação anterior, seu diário era para ela apenas um relato pobre e superficial de suas relações no interior do hospício e dos acontecimentos que vivenciava. Porém, ao "captar o já dito; reunir aquilo que se pôde ouvir ou ler, e isto com uma finalidade que não é nada menos do que a constituição de si" (Foucault, 1992, p.137), a perspectiva do diário como uma escrita de si é reativada, tendo este uma função terapêutica, funcionando como um cuidado de si:

Preciso escrever. Passei uma tarde horrorosa. Comecei a me sentir mal às quatro horas, e só agora, onze horas da noite, estou um pouco tranquila. (Cançado, 1991, p.32)

Escrevo sempre, isto me parece um ato de fé, de esperança. Ainda que tudo pareça perdido (...), ainda que tudo pareça perdido minha fé em mim mesma permanece. Nada consegue abalar a fé que tenho em mim. (Cançado, 1991, p.138).

Ora achando-se no dever de publicar o diário como forma de denunciar a vida na "cidade triste" e, assim, ensinar sobre o que não gostaria de estar vivendo; ora não desejando nada mais do que simplesmente escrever, porque isto era de fato o mais importante, Maura como já sabemos acabou por publicar seu diário alguns anos depois desta internação, em 1965. 
Esta oscilação entre o desejo de publicar ou não; a necessidade de escrever, mas a dificuldade em fazê -lo; a crença na qualidade de seu texto ou a descrença na validade do que escreve por ser uma "hospiciada", faz com que Maura ocupe o duplo lugar de escritora e escrevente, conforme enunciado por Barthes (1982). Ela é uma escritora! Assim se reconhece muitas vezes, defendendo seu lugar de distinção - por que escreve bem, por que é seu ofício, por que é reconhecida, por que publica o que escreve - frente àquelas outras muIheres que dentro dos hospícios tanto escrevem, mas cujas mensagens não tem sentido ou não chegam a lugar algum. Mas é também uma escrevente! Isto pois usa o seu diário como forma de testemunhar sobre o cotidiano institucional; de explicar sua experiência, e de suas colegas de internação, com a loucura (a menina bonita e promessa de coisas boas que tornou-se uma "hospiciada"); e ainda, de ensinar como resistir ao mundo do hospício.

Maura foi escrevente e escritora. Biógrafa de si e de outras. Sua narrativa é marcada pela intersecção entre o testemunhado e a ficção, recurso de que se valem (quase ou sempre) os escritores. Obedece seu texto ora a ordem do vivido, ora a ordem literária (com seus procedimentos próprios, figuras de linguagem e

\section{NOTAS}

1. O Centro Psiquiátrico Nacional passou a chamar-se, a partir de 1965, Centro Psiquiátrico Pedro II e em 1999, com a municipalização do atendimento à saúde no Rio de Janeiro, Instituto Municipal de Assistência à Saúde Nise da Silveira. Atualmente denomina-se Instituto Municipal Nise da Silveira.

2. As instituições locais subordinadas ao Serviço Nacional de Doenças Mentais eram: Centro Psiquiátrico Nacional, Colônia Juliano Moreira, Manicômio Judiciário Heitor Carrilho e Escola de Enfermagem Alfredo Pinto, sendo que apenas os dois primeiros tinham funções exclusivamente assistenciais médicas. (Braga, 2013)

3. Braga (2013) afirma que além das instituições pertencentes ao SNDM - ambulatórios de higiene mental e o CPN - havia duas outras portas de entrada para quem necessitasse de assistência no RJ, o Instituto de Psiquiatria da Universidade do Brasil e os serviços privados, para quem podia pagar.

4. Segundo Dias (2003, p.55), Nise da Silveira "chamou de psiquiatria tradicional os trabalhos e métodos de tratamento mais utilizados pela psiquiatria brasileira naquele momento. Na sua visão, divulgada muito tempo depois do prestígio adquirido pela STO e pelo MII, os tratamentos da época eram de ênfase extremamente organicista, onde as explicações acerca das causas dos transtornos mentais e de comportamentos resultariam de distúrbios biológicos e endócrinos, elementos estilísticos). Em relação ao cotidiano institucional do CPN, que visualizamos por meio das coisas ditas por Maura, motivadas segundo ela - e como lemos -, por desejos conflituosos de ensinar a outrem ou cuidar de si mesma, é certo que o texto de Maura é também um contundente documento que se contrapõe às histórias oficiais da própria instituição ou da assistência psiquiátrica em geral, ou mesmo à história crítica construída por Nise da Silveira a partir de seu trabalho no STO do CPN e no MII. Constitui-se assim sua narrativa como uma terceira via interpretativa? Não me parece ser esta a resposta correta. Prefiro dizer apenas que as coisas ditas por Maura são um instrumento portador de uma verdade ou, simplesmente, uma das verdades sobre o CPN, sobre as práticas dos diversos agentes no campo "psi", sobre a loucura e o louco, este "sofredor do ver" (Cançado, 1968).

\section{AGRADECIMIENTOS}

$\mathrm{O}$ artigo foi realizado com apoio do $\mathrm{CNPq}$, Conselho Nacional de Desenvolvimento Científico e Tecnológico Brasil e apresenta resultados do projeto de pesquisa "O ponto de vista dos loucos em percursos historiográficos e antologias de vidas". Processo: 309172/2015-2 - Chamada: Produtividade em Pesquisa - PQ 2015.

desconsiderando as explicações psicogênicas ou deixando -as em um lugar secundário. Essas explicações, de base cartesiana, é que justificariam o uso do eletrochoque, do coma insulínico, das psicocirurgias e das quimioterapias."

5. Maiores detalhes sobre a organização do STO no CPN, cf. Dias (2003); sobre o desenvolvimento deste tipo de serviço no CPN e em outros hospitais, na época, cf. Braga (2013).

6. O trecho citado foi originalmente publicado no livro: Silveira (1980), p. 13.

7. O trecho citado foi originalmente publicado no artigo: Silveira (1966), p. 47.

8. A perspectiva defendida por Nise da Silveira "de uma psiquiatria humanística, ciência estreitamente vinculada às demais ciências do homem" (Silveira, 2015, p.14), seu desejo de mergulhar no mundo interno dos esquizofrênicos, imagens das obras produzidas por estes (pertencentes ao acervo do MII) e as tentativas de compreensão das mesmas via a psicologia junguiana, podem ser vistas no livro Imagens do Inconsciente (primeira edição de 1981), um dos produtos de um período que se inicia logo após a aposentadoria compulsória de sua autora, em 1975, e que se revela muito intenso em reflexões sobre sua longa, criativa e frutífera obra. Para melhor entender os desdobramentos do trabalho de Nise 
da Silveira frente ao STO e ao MII, os embates constantes dela e sua equipe com a psiquiatria tradicional, para além do período enfocado neste texto,cf. também (Melo, 2001; Dias, 2003; Mello, 2014).

9. Segundo Scaramella (2010, p.84): "Entre sua primeira publicação no SDJB, em 1958, e sua última publicação neste mesmo suplemento, em 1961, Maura esteve seis vezes internada no Engenho de Dentro, o que não a impediu de escrever e publicar a maioria de seus contos neste período."

10.A primeira edição de Hospício é Deus é de 1965, publicada por José Álvaro Editor; a segunda é de 1979, publicada pela Record; a terceira, a que utilizo neste texto, é de 1991 e foi publicada pelo Círculo do Livro. Em 2015, a Autêntica Editora publicou uma caixa contendo os dois livros de Maura.

11. Sobre a vida e obra de Lima Barreto há uma produção abundante, cf. por exemplo, (Hidalgo, 2008; Arantes, 2008). Sobre a vida e obra de Rodrigo de Souza Leão, cf. Parteka (2016). Há também, no Brasil, um conjunto de trabalhos com fontes narrativas produzidas por pessoas infames, como os de

\section{BIBLIOGRAFIA}

Arantes, Marco Antonio (2008), "Hospício de doutores", História, Ciências, Saúde - Manguinhos, 15 (1), pp.35-52, [en línea], disponible en: http://www.scielo.br/pdf/hcsm/v15n1/04.pdf [consultado el 03/02/2017]

Autran, Margarida (1991), "Posfácio: Ninguém visita a interna do cubículo 2". En: Cançado, Maura Lopes, Hospício é Deus, 3. ed., São Paulo, Círculo do Livro, pp. 185-189.

Assis Brasil, Francisco de (1973), A Nova Literatura III - O Conto. História Crítica da Literatura Brasileira, Rio de Janeiro, Americana, Brasília, INL.

Barreto, Lima (2010), Cemitério dos Vivos; Diário do Hospício, São Paulo, Cosac Naify.

Barthes, Roland (1982), Crítica e verdade, São Paulo, Perspectiva.

Braga, André Luiz de Carvalho (2013), O Serviço Nacional de Doenças Mentais no governo JK: a assistência psiquiátrica para o Distrito Federal, Dissertação de Mestrado, Rio de Janeiro, Fundação Oswaldo Cruz, Programa de Pós-Graduação em História das Ciências e da Saúde, [en línea], disponible en: http://ppghcs.coc.fiocruz.br/images/dissertacoes/dissertacao_andre_braga.pdf. [consultado el 02/12/2016].

Borges, Viviane Trindade (2010), Do esquecimento ao tombamento: a invenção de Arthur Bispo do Rosário, Tese de Doutorado, Porto Alegre, Universidade Federal do Rio Grande do Sul, Programa de Pós-Graduação em História.

Bosi, Alfredo (2010), “Prefácio: O Cemitério dos Vivos: testemunho e ficção". En: Barreto, Lima, Cemitério dos Vivos; Diário do Hospício, São Paulo, Cosac Naify, pp.11-39.
(Wadi, 2009, 2010, 2011; Borges, 2010; Santos, 2005, 2008; Muñoz, 2010; Zara, 2014; Wadi e Zara, 2016).

12. A maior parte dos estudos sobre Maura são oriundos do campo acadêmico da Literatura, como os de (Telles, 2008; Silva, 2008, 2011; Musili, 2014), mas há também interessantes estudos oriundos das Ciências Humanas, como os de (Scaramella, 2010, 2015; Cordeiro, 2014).

13. Entendo jogo (jogo de verdade) na perspectiva de Foucault (2006b, p.282): “...quando digo 'jogo', me refiro a um conjunto de regras de produção de verdade. Não um jogo no sentido de imitar ou de representar...; é um conjunto de procedimentos que conduzem a um certo resultado, que pode ser considerado, em função de seus princípios e das suas regras de procedimento, válido ou não, ganho ou perda".

14. Esta percepção surgiu a partir de um trecho da primeira parte: "Procurei retratar-me até os dezessete anos, embora fatos ocorridos dentro desta idade estejam registrados neste diário, em minhas conversas com o médico." (Cançado, 1991, p.26.)

Cançado, Maura Lopes (1991), Hospício é Deus. Diário I. 3. ed., São Paulo, Círculo do Livro.

Cançado, Maura Lopes (1968), O sofredor do ver, Rio de Janeiro, José Alvaro Editor.

Cordeiro, Solange (2014), Discurso e escrita de si na obra Hospício é Deus de Maura Lopes Cançado, Dissertação de Mestrado, Marechal Cândido Rondon, Universidade Estadual do Oeste do Paraná, Programa de Pós-Graduação em História, Poder e Práticas Sociais.

Dias, Paula Barros (2003), Arte, Loucura e Ciência no Brasil: as origens do Museu de Imagens do Inconsciente, Dissertação de Mestrado, Rio de Janeiro, Fundação Oswaldo Cruz, Programa de Pós-Graduação em História das Ciências e da Saúde, [en línea], disponible en: http://www.ppghcs.coc.fiocruz. br/images/teses/diaspb.pdf [consultado el 02/12/2016]

Foucault, Michel (1987), Arqueologia do Saber, 3. ed., Rio de Janeiro, Forense Universitária.

Foucault, Michel (1992), "A escrita de si". En: Foucault, Michel. O que é um autor?, Lisboa, Vegas, Passagens, pp. 127-160.

Foucault, Michel. (2006a), "Polêmica, política e problematizações". En: Foucault, Michel. Ditos e escritos V: Ética, sexualidade, política, 2. ed., Rio de Janeiro, Forense Universitária, pp. 225-233.

Foucault, Michel (2006b), "A ética do cuidado de si como prática da liberdade". En: Foucault, Michel. Ditos e escritos V: Ética, sexualidade, política, 2. ed., Rio de Janeiro, Forense Universitária, pp. 264-287. 
Goffman, Erving (1999), Manicômios, prisões e conventos, 9. ed., São Paulo, Perspectiva.

Hidalgo, Luciana (2008), Literatura da urgência: Lima Barreto no domínio da loucura, São Paulo, Annablume.

Jorge, Marco Aurelio Soares (1997), Engenho dentro de casa: sobre a construção de um serviço de atenção diária em saúde mental, Dissertação de Mestrado, Rio de Janeiro, Fundação Oswaldo Cruz, Programa de Pós-Graduação em Saúde Pública, [en línea], disponible en: http://portalteses.icict. fiocruz.br/pdf/FIOCRUZ/1997/jorgemasm/capa.pdf [consultado el 02/12/2016]

Leão, Rodrigo de Souza (2010), Todos os Cachorros são Azuis, 2. ed., Rio de Janeiro, 7Letras.

Meireles, Murilo (2016), “Perfil biográfico”. En: Cançado, Maura Lopes. Hospício é Deus. Diário I., 5. ed., Belo Horizonte, Autêntica Editora, pp.203-227.

Melo, Walter (2001), Nise da Silveira, Rio de Janeiro/Brasília, Imago/CPF.

Mello, Luiz Carlos (2014), Nise da Silveira, caminhos de uma psiquiatra rebelde, Rio de Janeiro, Automática Edições Ltda.

Muñoz, Pedro Felipe Neves de (2010), Degeneração atípica: uma incursão ao arquivo de Elza. Dissertação de Mestrado, Rio de Janeiro, Fundação Oswaldo Cruz, Programa de Pós-Graduação em História das Ciências e da Saúde, [en línea], disponible en: http://www.ppghcs.coc.fiocruz.br/ images/teses/dissertacao_pedromunoz.pdf [consultado el 07/02/2017]

Musili, Célia (2014), Literatura e loucura, a transcendência pela palavra. Dissertação de Mestrado, Campinas, Universidade Estadual de Campinas, Instituto de Estudos da Linguagem, [en línea], disponible en: http://repositorio. unicamp.br/jspui/handle/REPOSIP/269874 [consultado el 02/02/2017]

Parteka, Thamara (2016), Rodrigo de Souza Leão: esquizofrenia e literatura na composição da vida como obra de arte (Rio de Janeiro, 1985-2009), Dissertação de Mestrado, Marechal Cândido Rondon, Universidade Estadual do Oeste do Paraná, Programa de Pós-Graduação em História, Poder e Práticas Sociais, [en línea], disponible en: http://tede.unioeste. $\mathrm{br} /$ handle/tede/1735 [consultado el 01/02/2017]

Santos, Nádia Maria Weber (2005), Histórias de vidas ausentes: a tênue fronteira entre a saúde e a doença mental, Passo Fundo, Ed. da UPF.

Santos, Nádia Maria Weber (2008), Narrativas da loucura e histórias de sensibilidades, Porto Alegre, Editora da UFRGS.

Scaramella, Maria Luisa (2010), Narrativas e sobreposições: notas sobre Maura Lopes Cançado, Tese de Doutorado, Cam- pinas, Universidade Estadual de Campinas, Instituto de Filosofia e Ciências Humanas, [en línea], disponible en: http:// repositorio.unicamp.br/jspui/handle/REPOSIP/280706 [consultado el 01/02/2017]

Scaramella, Maria Luisa (2015), "Fragmentos da vida de Maura Lopes Cançado: ou sobre os modelos e práticas de instituições psiquiátricas no Brasil entre as décadas de 1950 e 1980". En: Silva, I. C. da, Pignatelli, M., Viegas, S. de M. (eds.), Livro de Atas do 1o Congresso da Associação Internacional de Ciências Sociais e Humanas em Língua Portuguesa, Lisboa, Associação Internacional de Ciências Sociais e Humanas em Língua Portuguesa, pp. 1077-1094, [en línea], disponible en: http://hdl.handle.net/10451/20797 [consultad el 07/02/207]

Silva, Gislene Maria Barral Lima Felipe da (2008). Olhando sobre o muro: Representações de loucos na literatura brasileira contemporânea, Tese de Doutorado, Brasília-DF, Universidade de Brasília, Programa de Pós- Graduação em Literatura, [en línea], disponible en: http://repositorio.unb.br/handle/10482/1679 [consultado el 01/02/2017]

Silva, Gislene Maria Barral Lima Felipe da (2011), "Literatura, loucura e autoria feminina: Maura Lopes Cançado em sua autorrepresentação da escritora louca", Pontos de Interrogação, 1(1), pp. 87-100, [en línea], disponible en: http:// www.poscritica.uneb.br/revistaponti/arquivos/v1n1/07-LITERATURA-LOUCURA-E-AUTORIA-revistaponti-vol-n1.pdf [consultado el 07/02/2017]

Silveira, Nise (1980), Museu de Imagens do Inconsciente, Rio de Janeiro, Funarte.

Silveira, Nise (1966). "Vinte anos de terapêutica ocupacional em Engenho de Dentro (1946-1966)". Revista Brasileira de Saúde Mental, 5 (XII), Rio de Janeiro, pp. 18-159, p. 47, no editado.

Silveira, Nise da (2015), Imagens do inconsciente, 5. ed., Petrópolis, Vozes.

Telles, Norma (2008), "Cidade triste". En: Anais do Fazendo Gênero 8 - Corpo, Violência e Poder, Florianópolis, UFSC, s.p., [en línea], disponible en: http://www.fazendogenero. ufsc.br/8/sts/ST14/Norma_Telles_14.pdf [consultado el: 01/03/2017]

Wadi, Yonissa Marmitt (2009), A história de Pierina: subjetividade, crime e loucura, Uberlândia, EDUFU.

Wadi, Yonissa Marmitt (2010), “Um lugar (im)possível: narrativas sobre o viver em espaços de internamento". En: Wadi, Yonissa Marmitt; Santos, Nádia Maria Weber (org.) História e Loucura: saberes, práticas e narrativas, Uberlândia, EDUFU, pp. 331-362.

Wadi, Yonissa Marmitt (2011), "Entre muros: os loucos contam o hospício", Topoi, 12, pp. 250-269. 
Wadi, Yonissa M. y Zara, Telma Beiser de Melo (2016), “Problematizando o mundo: vida institucional e subjetivação no 'falatório' de Stela do Patrocínio". En: Wadi, Yonissa M. (org.), Narrativas sobre loucuras, sofrimentos e traumas, Curitiba, Máquina de Escrever, pp. 65-91.

Zara, Telma Beiser de Melo (2014), Me transformei com esse falatório todinho: cotidiano institucional e processo de sub- jetivação em Stela do Patrocínio, Dissertação de Mestrado, Toledo, Universidade Estadual do Oeste do Paraná, Programa de Pós-Graduação em em Ciências Sociais, [en línea], disponible en: http://portalpos.unioeste.br/media/File/ ciencias_sociais/Disserta\%C3\%A7\%C3\%A3o(5).pdf [consultado el 01/02/2017] 